\title{
The Relationship of Intimate Partner Violence With Psychiatric Disorders and Severity of Pain Among Female Patients With Fibromyalgia
}

\author{
Nermin GÜNDÜZ1 ${ }^{10}$, Erkal ERZINNCAN² ${ }^{10}$, Aslihan POLAT ${ }^{3}$ (D) \\ ${ }^{1}$ Department of Psychiatry, Kütahya University of Health Sciences, Kütahya, Turkey \\ ${ }^{2}$ Department of Psychiatry, Erenköy Mental Health Neurology Training and Research Hospital, Istanbul, Turkey \\ ${ }^{3}$ Department of Psychiatry, Kocaeli University Faculty of Medicine, Kocaeli, Turkey
}

\begin{abstract}
Objectives: This study aims to compare the prevalence of intimate partner violence and comorbid psychiatric disorders among patients with fibromyalgia syndrome (FMS) and healthy controls and also to investigate the relationship of intimate partner violence with psychiatric disorders and severity of pain in FMS patients.

Patients and methods: The study group consisted of 136 females including 68 patients with FMS (mean age $43 \pm 10.4$ years; range, 25 to 70 years) and 68 FMS-free healthy females (mean age 38.5 \pm 11.3 years; range, 22 to 70 years). Following a Structured Clinical Interview for Diagnostic and Statistical Manual-IV Axis I Disorders by a psychiatrist experienced in psychological trauma, Hamilton Depression Rating Scale (HDRS), Hamilton Anxiety Rating Scale (HARS), visual analog scale (VAS) for the severity of pain and Domestic Violence Against Women Scale (DVAWS) were applied.

Results: In FMS group, 85\% of the patients were diagnosed with mood or anxiety disorder. Almost half of these patients had major depressive disorder. The total scores of DVAWS and all subscales were significantly higher in the FMS group than in the control group ( $\mathrm{p}<0.01$ ). The severity of domestic violence were related to the presence of any psychiatric disorder only in FMS patients ( $p<0.01)$. Almost half of the FMS patients with high DVAWS score had comorbid mood and anxiety disorders. There was a significant positive correlation between the total scores of DVAWS, HDRS, HARS, and VAS $(p<0.01)$.

Conclusion: Although the etiology of FMS is still uncertain, psychosocial factors may play role as risk factors. Therefore, a multidisciplinary approach to the treatment should be considered.

Keywords: Anxiety; depression; domestic violence; fibromyalgia syndrome; intimate partner violence; pain.
\end{abstract}

Fibromyalgia syndrome (FMS) is a non-articular rheumatic disease characterized by chronic, widespread body pain in combination with excessive tenderness at specific anatomical sites. ${ }^{1}$ It is more prevalent in females than males and complaints such as fatigue, sleep disturbances, deterioration of cognitive functions, anxiety and depression are frequently reported in these patients. ${ }^{2}$ Although the etiology of FMS is still unknown, recent investigations reveal that psychosocial stress factors might well play a role. ${ }^{3}$ It has been reported that not only life-time sexual and physical abuse $e^{4,5}$ but also emotional abuse and neglect prevalences are higher in FMS patients. ${ }^{5}$ The abnormal responses to stress response stimulating factors are considered to play a crucial role in the emergence of FMS. The responses of the neuroendocrinological system

Received: July 01, 2018 Accepted: August 27, 2018 Published online: January 28, 2019

Correspondence: Nermin Gündüz, MD. Kütahya Sağlık Bilimleri Üniversitesi, Psikiyatri Anabilim Dalı, 43000 Kütahya, Turkey. Tel: +90 274 - 2652286 e-mail: ngunduz2798@hotmail.com 
of these patients to the stressors are different. ${ }^{6}$ This disturbance in the neuroendocrinological response may be genetic or due to stressful life events like history of abuse. ${ }^{7}$ Trauma and major life stress likely do not cause FMS per se but may trigger the symptoms in susceptible individuals. There is no doubt that experience of an abusive relationship is a maintained stress situation. In this context, intimate partner violence against females should also be considered as one of the possible persistent risk factors in the emergence of FMS. ${ }^{8}$

Domestic violence against females is regarded as an important public health problem leading to physical and mental health problems. ${ }^{9}$ In addition to psychiatric disorders, one of the major reasons for the violence victims to apply to health institutions is chronic pain. ${ }^{9}$ Thus, it is important to consider domestic violence in the diagnosis of patients with unexplained chronic pain such as headache, myofascial pain and fibromyalgia. ${ }^{11,12}$ There are several studies yielding higher prevalence of certain types of lifetime abuse in $\mathrm{FMS}^{12}$ while there is only one study from Turkey exploring the relationship of domestic violence and FMS, to the best of our knowledge. ${ }^{13}$

Given the dearth of the literature and the importance of cultural issues on this topic, in this study, we aimed to compare the prevalence of intimate partner violence and comorbid psychiatric disorders among patients with FMS and healthy controls and also to investigate the relationship of intimate partner violence with psychiatric disorders and severity of pain in FMS patients.

\section{PATIENTS AND METHODS}

The study included 68 consecutive female patients (mean age $43 \pm 10.4$ years; range, 25 to 70 years) who applied to the outpatient clinic of Kocaeli University Medical Faculty Physical Medicine and Rehabilitation Department between February 2014 and June 2014 and diagnosed as FMS by a physician according to the American College of Rheumatology 2010 criteria for FMS. ${ }^{14}$ Patients who were illiterate, who had significant visual, hearing and cognitive impairment of communication, accompanied by inflammatory rheumatic disease or autoimmune disease, patients with mental retardation or psychotic disorder, those with steroid or substance use, or those with chronic neurological disease with significant cognitive decline were excluded. Control group consisted of 68 females (mean age $38.5 \pm 11.3$ years; range, 22 to 70 years) recruited from the volunteering relatives of patients who applied to Ear Nose Throat Department and who were not diagnosed with FMS. Control group was also questioned in terms of the exclusion criteria. Toxicology drug screening was performed to exclude substance abuse. In order to guarantee females' safety, patients who were accompanied by their husbands were excluded, following the "Ethical and Safety Recommendations for Research on Domestic Violence Against Women". ${ }^{15}$ The study protocol was approved by the Kocaeli University Medical Faculty Ethics Committee (Ethics ID: 2014/55). A written informed consent was obtained from each participant. The study was conducted in accordance with the principles of the Declaration of Helsinki.

\section{Instruments}

Sociodemographic Data Form: In this form, participants were asked about personal information like age, marital status, educational status, working status, income level, additional medical illnesses, current smoking, alcohol use and history of psychiatric disorders.

Structured Clinical Interview for Diagnostic and Statistical Manual-IV Axis I Disorders (SCID-I): This is a semi-structured clinical interview developed for use by mental health professionals. ${ }^{16}$ SCID-I allows to diagnose both present and life-time axis I mental disorders. In this study, we used the modules for depression and anxiety disorders only and focused on the current diagnoses.

Hamilton Depression Rating Scale (HDRS): This 17-item scale questioning the depressive complaints in the last week is administered by the physician. ${ }^{17}$ The scoring is as follows: 0-7 points indicate "no depression", 8-15 points indicate "mild depression", 16-28 points indicate "moderate depression", and 29 points and above indicate "severe depression". The Turkish version of the form was validated. ${ }^{18}$

Hamilton Anxiety Rating Scale (HARS): This physician-administered scale consists 
of 14 questions about both psychological and physical symptoms of anxiety. ${ }^{19}$ It is evaluated as follows: $0-5$ points indicate "no anxiety", 6-14 points indicate minor anxiety", and 15 points and above indicate "major anxiety". The Turkish version of the form was validated. ${ }^{20}$

Visual analog scale (VAS): This scale is used to determine the severity of pain. VAS is a $10 \mathrm{~cm}$ line, left side representing no pain and right side representing intolerable pain. Patients were asked to mark the severity of the pain they felt on this line. Then, the distance to the starting point of the marking was measured with a ruler and recorded..$^{21}$

Domestic Violence Against Women Scale (DVAWS): This five-point likert-type scale, which was designed by Yanikkerem and Saruhan ${ }^{22}$ for Turkish female population, consists of 90 questions. The Cronbach's alpha reliability coefficient for the scale is 0.979 . The scale has nine subscales as physical violence (damaging the integrity of female's body); emotional violence such as insult, contempt; economic violence; social violence and isolation of female; contempt of the sex of the female and threatening behaviors against female; sexual violence against female; negative affectivity of the female towards herself; worries and fears about husband; the use of male privilege and the lack of sharing in marriage. Scoring is as follows: $0-2.00$ is interpreted as very low; 2.01-4.00 as low; 4.01-6.00 as moderate; 6.01-8.00 as high and 8.01-10.00 as very high level of violence.

\section{Statistical analysis}

The data obtained in the study were analyzed using the Statistical Program for Social Sciences version 16.0 (SPSS Inc., Chicago, IL, USA). Chi square test was used to compare categorical data. Normal distribution of numerical variables was investigated by visual (histogram and probability graphs) and analytical methods (KolmogorovSmirnov test). T-test was used for binary comparison of numerical data with normal distribution. For the analysis of non-normally distributed numerical data, Mann-Whitney $U$ test was used to compare two groups. The relationship between numerical variables with non-normal distribution was

Table 1. Sociodemographic characteristics of fibromyalgia syndrome patients and healthy controls

\begin{tabular}{|c|c|c|c|c|c|}
\hline & \multicolumn{2}{|c|}{ FMS patients } & \multicolumn{2}{|c|}{ Healthy controls } & \multirow[b]{2}{*}{$p$} \\
\hline & $\mathrm{n}$ & $\%$ & $\mathrm{n}$ & $\%$ & \\
\hline $\begin{array}{l}\text { Marital status } \\
\text { Married } \\
\text { Divorced/widower }\end{array}$ & $\begin{array}{l}48 \\
20\end{array}$ & $\begin{array}{l}70.6 \\
29.4\end{array}$ & $\begin{array}{c}64 \\
4\end{array}$ & $\begin{array}{c}94.1 \\
5.9\end{array}$ & $<0.01$ \\
\hline $\begin{array}{l}\text { Educational status } \\
\text { Elementary school } \\
\text { Secondary school and high school } \\
\text { College }\end{array}$ & $\begin{array}{l}37 \\
16 \\
15\end{array}$ & $\begin{array}{l}54.4 \\
23.5 \\
22.1\end{array}$ & $\begin{array}{l}22 \\
20 \\
26\end{array}$ & $\begin{array}{l}32.4 \\
29.4 \\
38.2\end{array}$ & $<0.01$ \\
\hline $\begin{array}{l}\text { Working status } \\
\text { Yes }\end{array}$ & 38 & 55.9 & 47 & 69.1 & 0.111 \\
\hline $\begin{array}{l}\text { Socioeconomic status } \\
\text { Low } \\
\text { Moderate } \\
\text { High }\end{array}$ & $\begin{array}{l}22 \\
32 \\
14\end{array}$ & $\begin{array}{l}32.4 \\
47.1 \\
20.6\end{array}$ & $\begin{array}{c}9 \\
45 \\
14\end{array}$ & $\begin{array}{l}13.2 \\
66.2 \\
20.6\end{array}$ & 0.087 \\
\hline $\begin{array}{l}\text { Current smoking } \\
\text { Yes }\end{array}$ & 26 & 38.2 & 15 & 22.1 & 0.040 \\
\hline $\begin{array}{l}\text { Alcohol } \\
\text { Yes }\end{array}$ & 9 & 13.2 & 4 & 5.9 & 0.243 \\
\hline $\begin{array}{l}\text { Accompanying medical disorder } \\
\text { Yes }\end{array}$ & 55 & 80.9 & 29 & 42.6 & $<0.01$ \\
\hline $\begin{array}{l}\text { History of psychiatric disorder } \\
\text { Yes }\end{array}$ & 50 & 84.5 & 14 & 20.6 & $<0.01$ \\
\hline $\begin{array}{l}\text { Family history of psychiatric disorder } \\
\text { Yes }\end{array}$ & 31 & 45.6 & 12 & 17.6 & $<0.01$ \\
\hline
\end{tabular}




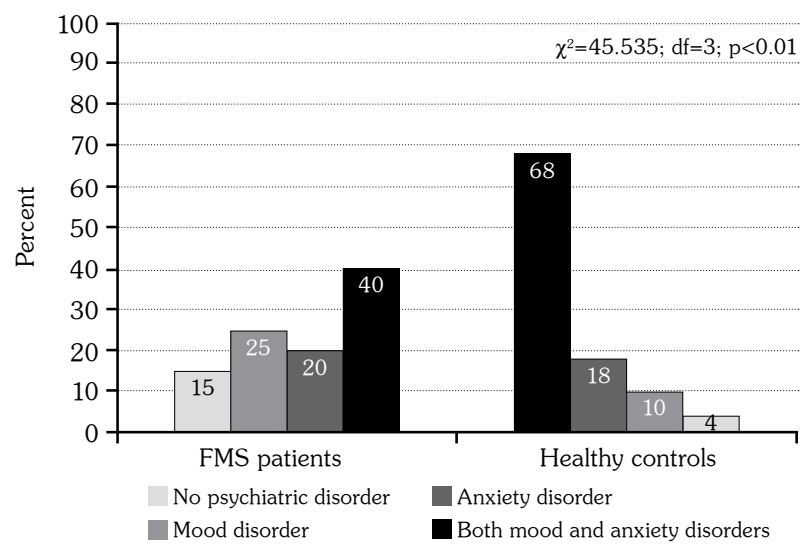

Figure 1. Distribution of mood and anxiety disorders among study groups. FMS: Fibromyalgia syndrome.

investigated by Spearman correlation analysis. A $p$ value $<0.05$ was considered statistically significant.

\section{RESULTS}

Mean ages were $43 \pm 10.4$ years for FMS patients and $38.5 \pm 11.3$ for healthy controls $(p=0.017)$. Sociodemographic characteristics are presented in Table 1.

The rate of patients diagnosed with any mood or anxiety disorder using SCID-I was significantly higher in FMS group (85\%) compared to healthy control group $(32 \%)(p<0.01)$. The distribution of psychiatric comorbidity in general is shown in Figure 1. While major depressive disorder (42.6\%) was the most common psychiatric diagnosis in females with FMS, the percentage of patients with post-traumatic stress disorder was also quite high (14.7\%). The distribution of mood and anxiety disorders among study groups is presented in Table 2.

The median level of domestic violence evaluated with total score of DVAWS was 4.66 (interquartile range $[\mathrm{IQR}]=3.46$ ) in females with FMS. Although almost all subtypes of violence were significantly higher in FMS group, the highest subscale score belonged to "negative affectivity of the female towards herself" with a median score of $6.5(\mathrm{IQR}=4.38)$ (Table 3). The number of FMS patients with DVAWS total score higher than 6 (high) was 24 (35.2\%). Of these FMS patients reporting high levels of domestic violence, seven (29.1\%) had mood disorders, four (16.7\%) had anxiety disorders, and 13 (54.2\%) had both mood and anxiety disorders.

We compared the domestic violence (DVAWStotal) scores with regard to the presence of any psychiatric disorder among study groups (Table 4). Only in FMS group, DVAWS scores were significantly higher in patients with any psychiatric disorder compared to that of patients without psychiatric diagnosis $(p<0.01)$.

In addition to actual psychiatric diagnoses with SCID-I, mean anxiety and depression levels were determined by HARS and HDRS to investigate the correlation with pain and domestic violence levels. Mean HARS scores were $22.28 \pm 13.32$ in FMS group and

Table 2. Comorbid psychiatric disorders

\begin{tabular}{|c|c|c|c|c|c|}
\hline & \multicolumn{2}{|c|}{ FMS patients } & \multicolumn{2}{|c|}{ Healthy controls } & \multirow[b]{2}{*}{$p$} \\
\hline & $\mathrm{n}$ & $\%$ & $\mathrm{n}$ & $\%$ & \\
\hline $\begin{array}{l}\text { Mood disorders } \\
\text { Major depressive disorder } \\
\text { Dysthymic disorder } \\
\text { Depressive disorder, not otherwise specified }\end{array}$ & $\begin{array}{c}29 \\
6 \\
9\end{array}$ & $\begin{array}{c}42.6 \\
8.8 \\
13.2\end{array}$ & $\begin{array}{l}4 \\
3 \\
8\end{array}$ & $\begin{array}{c}5.9 \\
4.4 \\
11.8\end{array}$ & $<0.01$ \\
\hline $\begin{array}{l}\text { Anxiety disorder } \\
\text { Panic disorder } \\
\text { Obsessive compulsive disorder } \\
\text { General anxiety disorder } \\
\text { Social anxiety disorder } \\
\text { Anxiety disorder, not otherwise specified } \\
\text { Post-traumatic stress disorder }\end{array}$ & $\begin{array}{c}4 \\
8 \\
5 \\
2 \\
12 \\
10\end{array}$ & $\begin{array}{c}5.9 \\
11.8 \\
7.4 \\
2.9 \\
17.6 \\
14.7\end{array}$ & $\begin{array}{l}3 \\
0 \\
0 \\
2 \\
5 \\
0\end{array}$ & $\begin{array}{c}4.4 \\
0 \\
0 \\
2.9 \\
7.4 \\
0\end{array}$ & $<0.01$ \\
\hline
\end{tabular}


Table 3. Characteristics of domestic violence based on Domestic Violence Against Women Scale total and subscale scores

\begin{tabular}{|c|c|c|c|c|c|}
\hline & \multicolumn{2}{|c|}{ FMS patients } & \multicolumn{2}{|c|}{ Healthy controls } & \multirow[b]{2}{*}{$p$} \\
\hline & Median & IQR & Median & IQR & \\
\hline Physical violence & 3.27 & 3.38 & 2.07 & 0.38 & $<0.01$ \\
\hline Emotional violence & 5.25 & 3.75 & 2.25 & 1.50 & $<0.01$ \\
\hline Economic violence & 6.22 & 3.51 & 4.44 & 2.89 & $<0.01$ \\
\hline Social violence and isolation & 4.57 & 4.15 & 3.14 & 1.67 & $<0.01$ \\
\hline Contempt of the sex of the female and threatening behaviors & 3.66 & 4.39 & 2.22 & 0.88 & $<0.01$ \\
\hline Sexual violence & 5.14 & 3.36 & 2.28 & 1.71 & $<0.01$ \\
\hline Negative affectivity of the female towards herself & 6.5 & 4.38 & 3 & 1.50 & $<0.01$ \\
\hline Worries and fears about husband & 5.86 & 4.93 & 2.85 & 1.72 & $<0.01$ \\
\hline The use of male privilege and the lack of sharing in marriage & 6.1 & 3.55 & 4.2 & 2.00 & $<0.01$ \\
\hline The total score of Domestic Violence Against Women Scale & 4.66 & 3.46 & 2.94 & 0.92 & $<0.01$ \\
\hline
\end{tabular}

Table 4. Comparison of domestic violence scores according to presence of any psychiatric disorder

\begin{tabular}{|c|c|c|c|c|c|c|c|}
\hline & \multicolumn{6}{|c|}{ DVAWS total score } & \multirow[b]{3}{*}{$p$} \\
\hline & \multicolumn{3}{|c|}{ Presence of any psychiatric disorder $(n=80)$} & \multicolumn{3}{|c|}{ No psychiatric disorder $(n=56)$} & \\
\hline & $\mathrm{n}$ & Median & IQR & $\mathrm{n}$ & Median & IQR & \\
\hline FMS patients $(n=68)$ & 58 & 4.84 & 3.54 & 10 & 2.85 & 1.68 & $<0.01$ \\
\hline Controls $(n=68)$ & 22 & 3.08 & 1.15 & 46 & 2.91 & 0.80 & 0.273 \\
\hline
\end{tabular}

$6.56 \pm 7.88$ in healthy controls $(p<0.01)$. Mean HDRS scores were $24.59 \pm 14.75$ in FMS group and $9.13 \pm 9.42$ in healthy controls $(p<0.01)$. In the FMS group, the mean VAS score was $6.25 \pm 2.03$, which was interpreted as moderate pain. Pain severity had positive correlations with both domestic violence levels and psychiatric measures. However, the strongest correlation of all was between DVAWS and VAS $(r=0.707$; $\mathrm{p}<0.01$ ) (Table 5).

Table 5. Correlation analysis in FMS patients

\begin{tabular}{lcll}
\hline & VAS & HARS & HDRS \\
\hline DVAWS & $0.707^{*}$ & $0.432^{*}$ & $0.330^{*}$ \\
VAS & & $0.490^{*}$ & $0.502^{*}$ \\
HARS & & & $0.327^{*}$ \\
\hline
\end{tabular}

FMS: Fibromyalgia syndrome; DVAWS: Domestic Violence Against Women Scale; VAS: Visual analog scale for pain; HARS: Hamilton Anxiety Rating Scale; HDRS: Hamilton Depression Rating Scale; ${ }^{*} \mathrm{p}<0.01$.

\section{DISCUSSION}

According to data obtained in our study, both psychiatric comorbidities and domestic violence were more common in FMS patients than in females without this syndrome. In terms of the relationship of domestic violence with regard to the presence of psychiatric comorbidity, we found a significant relationship only in FMS group. Furthermore, the severity of pain in FMS group showed positive correlation not only with the level of intimate partner violence but also with the level of depression and anxiety. There are several studies in the literature investigating the relationship between FMS and domestic violence; however, the number of studies with a detailed and structured psychiatric interview is scarce. Psychiatric questionnaires are mostly used for screening purposes rather than diagnostic purposes. The importance of the therapeutic relationship established during psychiatric interview is obvious to reach accurate results 
particularly in sensitive issues such as domestic violence. ${ }^{12}$ Thus, in our study, both SCID-I and DVAWS have been performed by a psychiatrist trained in psychological trauma. The patients in need for treatment were referred to the psychiatry outpatient clinic for further follow-up and treatment.

Approximately $85 \%$ of females with FMS in our study were diagnosed as having any mood or anxiety disorder. Furthermore, the fact that $40 \%$ of these patients had both mood and anxiety disorders showed a more severe condition. In accordance with previous studies, these findings support the association of psychological factors in FMS. $2,23,24$ Almost $43 \%$ of our FMS group were diagnosed as major depression, which is a serious clinical condition and needs appropriate psychiatric treatment. Posttraumatic stress disorder (PTSD), which might well be another important psychiatric disorder related to the presence of domestic violence, was diagnosed in $14.6 \%$ of FMS patients similar to the literature. ${ }^{25-27}$ These patients may constitute the high risk group in terms of compliance and treatment resistance, which emphasizes the importance of a multidisciplinary treatment approach including a psychiatrist.

Recently, it has been stated that environmental trigger factors may play a role in the etiopathogenesis of FMS. ${ }^{2}$ Studies have indicated that life-time sexual and physical abuse is associated with an increased risk for FMS. ${ }^{12}$ However, previous research mostly focused on childhood maltreatment in the etiology of FMS, ${ }^{23}$ whereas only a few studies have tried to explore the association with domestic violence against females. ${ }^{8}$ To our knowledge, there is only one study from Turkey investigating domestic violence in FMS. ${ }^{13}$ However, our study is the first where a structured clinical interview was held yielding valid psychiatric diagnoses in addition to the detailed domestic violence survey. Not only the total score but also all subtypes of domestic violence were higher in FMS group. The average DVAWS total score revealed moderate level of domestic violence in FMS group whereas it was low in the control group. Nevertheless, the subscales covering economic violence; negative affectivity of the female towards herself; and the use of male privilege and lack of sharing in marriage yielded high levels of violence in females with FMS. It is noteworthy to keep in mind that delicate subjects like intimate partner violence are not easy to explore in routine clinical practice and such issues may have many invisible and underestimated dimensions.

In a similar study conducted by Ruiz-Pérez et al., ${ }^{8}$ violence against females was reported to be more prevalent in FMS and psychological distress was found to be positively associated with FMS. Besides, they stressed that their finding about the consequences of emotional abuse as much as physical and sexual abuse in relation to FMS was a new contribution to the literature. In the study of Özer et al., ${ }^{13}$ which was conducted on 34 FMS patients with no control group, domestic physical violence was reported in $38.2 \%$ of the females. Unfortunately, lack of information about the types of domestic violence other than physical violence was stated as a limitation of the study. Nevertheless, the results of our study contribute to the literature reporting that abuse can trigger chronic pain disorders. ${ }^{5,8,23,28}$

Although abuse is speculated to play an important etiological role in patients with FMS, the factors mediating the link between FMS and abuse have often been overlooked. Since FMS has been associated with traumatic events in the literature, these patients might also present with higher levels of psychological distress. Female victims of domestic violence are already known to be at serious risk for anxiety, depression, PTSD and chronic pain. ${ }^{29,30}$

In our study, there was a significant relationship of domestic violence with the presence of psychiatric diagnoses only in FMS group. Also, almost half of the FMS patients reporting high level of domestic violence were diagnosed as having both mood and anxiety disorders. Our FMS group consisted of heterogeneous patients with no information about treatment response. Those patients with multiple psychiatric comorbidities might well constitute the high risk group in terms of compliance and treatment resistance as reported in previous research. ${ }^{31}$ Similarly, severity of pain showed positive correlation with both the total score of DVAWS and psychiatric measures of depression and anxiety levels, which is also consistent with the literature. . $^{13,32,33}$

The results of our study emphasize that domestic violence is related to anxiety, depression and severity of pain in females with FMS. 
However, given the cross-sectional design of the study, we are unable to conclude whether FMS is a consequence of this psychological distress or vice versa. There are inconsistent findings about FMS being a somatic presentation of psychological problems or the presence of FMS leading to higher rates of psychological distress. ${ }^{8}$ Nevertheless, this highlights the importance of an interdisciplinary approach to identify intimate partner violence and psychiatric disorders that may have harmful effects on the patient's ability to cope with her FMS symptoms and may lead to a poorer prognosis.

There are some limitations of our study. Our FMS group consisted of heterogeneous participants including either newly diagnosed or treatmentresistant patients. Furthermore, this study was performed on female patients seeking help. So, the results cannot be generalized to the general population. Female patients who admitted with their husbands were excluded. Ethical and Safety Recommendations for Research on Domestic Violence Against Women suggests the application of this exclusion criterion due to the possibility that domestic violence may be higher in this population. Admitting hospital with the husbands may indicate a male control over the female in most Western cultures but it is a controversial issue in our culture. Domestic violence seems to be associated with low sociocultural levels; however, illiterate females were excluded due to the study methodology. Usual possible self-reporting bias of such an intimate and socially unaccepted subject should also be kept in mind. Nevertheless, these limitations may have underestimated rather than overestimating the real prevalence of abuse and its associations.

In conclusion, FMS with ongoing controversies regarding its diagnosis and management, has become an important study field in recent years. It is associated with many physical and mental complaints in addition to pain. Although pharmacological treatment has prevailed to date, it is not totally satisfying. The association of intimate partner violence and FMS may provide a new perspective when considering alternative therapeutic strategies. Psychiatric evaluation and individualized analysis of each patient particularly in the context of treatment resistance may make significant contribution towards offering appropriate treatment and allowing an interdisciplinary approach. However, considering its consequences, questioning domestic violence should be a routine part of patients' examination, particularly in those with chronic pain.

\section{Declaration of conflicting interests}

The authors declared no conflicts of interest with respect to the authorship and/or publication of this article.

\section{Funding}

The authors received no financial support for the research and/or authorship of this article.

\section{REFERENCES}

1. Wolfe F, Smythe HA, Yunus MB, Bennett RM, Bombardier C, Goldenberg DL, et al. The American College of Rheumatology 1990 Criteria for the Classification of Fibromyalgia. Report of the Multicenter Criteria Committee. Arthritis Rheum 1990;33:160-72.

2. González E, Elorza J, Failde I. [Article in English, Spanish] Fibromyalgia and psychiatric comorbidity: their effect on the quality of life patients. Actas Esp Psiquiatr 2010;38:295-300.

3. Clauw DJ, Williams DA. Relationship between stress and pain in work-related upper extremity disorders: the hidden role of chronic multisymptom illnesses. Am $\mathrm{J}$ Ind Med 2002;41:370-82.

4. Boisset-Pioro MH, Esdaile JM, Fitzcharles MA. Sexual and physical abuse in women with fibromyalgia syndrome. Arthritis Rheum 1995;38:235-41.

5. Walker EA, Keegan D, Gardner G, Sullivan M, Bernstein D, Katon WJ. Psychosocial factors in fibromyalgia compared with rheumatoid arthritis: II. Sexual, physical, and emotional abuse and neglect. Psychosom Med 1997;59:572-7.

6. Neeck G. Neuroendocrine and hormonal perturbations and relations to the serotonergic system in fibromyalgia patients. Scand J Rheumatol Suppl 2000;113:8-12.

7. Weissbecker I, Floyd A, Dedert E, Salmon P, Sephton S. Childhood trauma and diurnal cortisol disruption in fibromyalgia syndrome. Psychoneuroendocrinology 2006;31:312-24.

8. Ruiz-Pérez I, Plazaola-Castaño J, Cáliz-Cáliz R, RodríguezCalvo I, García-Sánchez A, Ferrer-González MA, et al. Risk factors for fibromyalgia: the role of violence against women. Clin Rheumatol 2009;28:777-86.

9. Kendall-Tackett K, Marshall R, Ness K. Chronic pain syndromes and violence against women. $J$ Women \& Therapy 2003;26:1-2.

10. Rubin JJ. Psychosomatic pain: new insights and management strategies. South Med J. 2005;98:1099-110. 
11. Varjavand N, Cohen DG, Novack DH. An assessment of residents' abilities to detect and manage domestic violence. J Gen Intern Med 2002;17:465-8.

12. Häuser W, Kosseva M, Üceyler N, Klose P, Sommer C. Emotional, physical, and sexual abuse in fibromyalgia syndrome: a systematic review with meta-analysis. Arthritis Care Res (Hoboken) 2011;63:808-20.

13. Özer Ü, Selimoğlu E, Badur E, Uygun E, Karşıdağ Ç. Fibromiyalji olgularında aile içi fiziksel şiddetin ağrı şiddeti, depresyon ve anksiyete düzeyleri ile ilişkisi. Nobel Medikus 2015;31:27-32.

14. Wolfe F, Clauw DJ, Fitzcharles MA, Goldenberg DL, Katz RS, Mease P, et al. The American College of Rheumatology preliminary diagnostic criteria for fibromyalgia and measurement of symptom severity. Arthritis Care Res (Hoboken) 2010;62:600-10.

15. Putting women first: Ethical and safety recommendations for research on domestic violence against women. Geneva: World Health Organization; 2001.

16. Spitzer RL, Williams JB, Gibbon M, First MB. The Structured Clinical Interview for DSM-IV Axis I Disorders, Clinician Version (SCID-CV). Washington: American Psychiatric Press; 1996.

17. Williams JB. A structured interview guide for the Hamilton Depression Rating Scale. Arch Gen Psychiatry 1988;45:742-7.

18. Akdemir A, Örsel S, Dağ İ, Türkçapar HM, İşcan $\mathrm{N}$, Özbay $\mathrm{H}$. Hamilton derecelendirme ölçeğinin geçerliği, güvenirliği ve klinikte kullanımı. Psikiyatri Psikoloji Psikofarmakoloji Dergisi 1996;4:251-9.

19. Hamilton M. The assessment of anxiety states by rating. $\mathrm{Br}$ J Med Psychol 1959;32:50-5.

20. Yazıcı MK, Demir B, Tanrıverdi N, Karaağaoğlu E, Yolaç P. Hamilton Anksiyete Değerlendirme Ölçeği, değerlendiriciler arası güvenirlik ve geçerlik çalışması Türk Psikiyatri Dergisi 1998;9:114-7.

21. McCormack HM, Horne DJ, Sheather S. Clinical applications of visual analogue scales: a critical review. Psychol Med 1988;18:1007-19.

22. Yanıkkerem E, Saruhan A. 15-49 yaş evli kadınların aile içi şiddet konusunda görüşlerinin ve aile içi şiddete maruz kalma durumlarının incelenmesi. MN Klinik Bilimler \& Doktor 2005;11:198-204.

23. Gündüz N, Polat A, Erzincan E, Turan H, Sade I, Tural Ü. Psychiatric comorbidity and childhood trauma in fibromyalgia syndrome. Turk $J$ Phys Med Rehab
2018;64:91-9.

24. Thieme K, Turk DC, Flor H. Comorbid depression and anxiety in fibromyalgia syndrome: relationship to somatic and psychosocial variables. Psychosom Med 2004;66:837-44.

25. Taşkın EO, Tıkız C, Yüksel EG, Fırat A, Tüzün Ç, Aydemir Ö. Prevalance of depressive disorders among patients with fibromyalgia seeking help for the first time and its relationship with alexithymia. Anadolu psik derg 2007;8:248-55.

26. Cohen H, Neumann L, Haiman Y, Matar MA, Press J, Buskila D. Prevalence of post-traumatic stress disorder in fibromyalgia patients: overlapping syndromes or post-traumatic fibromyalgia syndrome? Semin Arthritis Rheum 2002;32:38-50.

27. Semiz M, Kavakçı Ö, Pekşen H, Tunçay MH, Özer Z, Semiz EA. Post-traumatic stress disorder, alexithymia and somatoform dissociation in patients with fibromyalgia. Turk J Phys Med Rehab 2014;60:245-51.

28. Van Houdenhove B, Neerinckx E, Lysens R, Vertommen H, Van Houdenhove L, Onghena P, et al. Victimization in chronic fatigue syndrome and fibromyalgia in tertiary care: a controlled study on prevalence and characteristics. Psychosomatics 2001;42:21-8

29. Symes L, McFarlane J, Nava A, Gilroy H, Maddoux J. The association of pain severity and pain interference levels with abuse experiences and mental health symptoms among 300 mothers: baseline data analysis for a 7-year prospective study. Issues Ment Health Nurs 2013;34:2-16.

30. Wuest J, Merritt-Gray M, Ford-Gilboe M, Lent B, Varcoe C, Campbell JC. Chronic pain in women survivors of intimate partner violence. $\mathrm{J}$ Pain 2008;9:1049-57.

31. Bradley LA. Psychiatric comorbidity in fibromyalgia. Curr Pain Headache Rep 2005;9:79-86.

32. Humphreys J, Cooper BA, Miaskowski C. Differences in depression, posttraumatic stress disorder, and lifetime trauma exposure in formerly abused women with mild versus moderate to severe chronic pain. $\mathrm{J}$ Interpers Violence 2010;25:2316-38.

33. Loevinger BL, Shirtcliff EA, Muller D, Alonso C, Coe CL. Delineating psychological and biomedical profiles in a heterogeneous fibromyalgia population using cluster analysis. Clin Rheumatol 2012;31:677-85. 